\title{
Tilbakefall etter elektrokonvulsiv terapi
}

Engelsk oversettelse av hele artikkelen på www.tidsskriftet.no

\section{Sammendrag}

Bakgrunn. Uansett behandlingsmetode er det stor tendens til tilbakefall av depresjon dersom behandlingen opphører. Formålet med denne retrospektive studien var å undersøke tilbakefallsprosenten og tid til tilbakefall etter elektrokonvulsiv behandling (ECT) og hva som ble gjort for å forebygge dette.

Materiale og metode. ECT-protokollene og journalene til pasienter som fikk elektrokonvulsiv terapi i perioden 1960-95 ved tre psykiatriske avdelinger ved Dikemark sykehus ble systematisk gjennomgått. Tilbakefall ble definert som journalført klar tilbakekomst av depressive symptomer hos pasienter som hadde oppnådd bedring etter en serie med ECT-behandling. Observasjonstid er definert som tiden etter avsluttet første ECT-serie ved Dikemark til og med 31.12. 1995.

Resultater. Median observasjonstid etter pasientens første ECT-serie ved Dikemark var ni år (spredning: 3 md. -44 år). 56 av 120 pasienter (47\%) med beskrevet bedring etter første ECT-serie fikk tilbakefall i løpet av de første seks månedene. Totalt fikk 86 (72\%) tilbakefall etter gjennomsnittlig 13 måneder (median 3 md.), men ingen av de sju som ble bedre av sin førstegangsdepresjon fikk tilbakefall. Etter første ECT-serie fikk 84 pasienter (70\%) antidepressiver og/eller litium for å forebygge tilbakefall. Av 100 gjentatte ECT-serier gitt til 46 pasienter ble det beskrevet bedring etter 87 serier. I $58(67 \%)$ av disse forekom tilbakefall innen seks måneder.

Fortolkning. Tilbakefallsraten var høy. Resultatene tyder på at oppfølgende behandling med antidepressiver etter elektrokonvulsiv terapi bør suppleres med andre tiltak for å redusere tilbakefallsraten ved depresjon.

\section{Kjell Martin Moksnes}

kjell.martin.moksnes@ulleval.no

Alderspsykiatrisk avdeling

Klinikk psykisk helse og avhengighet

Oslo universitetssykehus

Elektrokonvulsiv terapi (ECT) har vanligvis rask og god effekt og få akutte bivirkninger (1).

Moderat til alvorlig depresjon er ofte tilbakevendende. I en studie med eldre pasienter vellykket behandlet for tilbakevendende depresjon med antidepressiver var tilbakefallsfrekvensen i løpet av tre år i ettervern $90 \%$ hos dem som fikk placebo, $64 \%$ hos dem som fikk interpersonlig psykoterapi pluss placebo, $43 \%$ hos dem som fikk nortriptylin og $20 \%$ hos dem som fikk nortriptylin pluss interpersonlig psykoterapi (2).

I studier fra de siste tiårene er det også også funnet høye tilbakefallsrater etter elektrokonvulsiv terapi. Sackeim og medarbeidere fant rater på $84 \%$ med placebo, $60 \%$ med nortriptylin alene og $39 \%$ med nortriptylin pluss litium innen seks måneder (3).

Målet med denne studien var å undersøke hvor stor andel som fikk tilbakefall etter ECT-behandling ved Dikemark sykehus, hvor lang tid det gikk til tilbakefallet og hva som ble gjort profylaktisk for å hindre dette.

\section{Materiale og metode}

Studien er basert på en gjennomgang av ECT-protokollene og pasientjournalene til alle som fikk elektrokonvulsiv terapi i perioden 1960-95 ved tre psykiatriske avdelinger ved Dikemark sykehus. 141 personer fikk totalt 241 serier og 1960 enkeltbehandlinger. 124 av 141 pasienter ( $88 \%$ ) hadde en stemningslidelse som hoveddiagnose. $\mathrm{Pa}$ sientene var i stor grad blitt forsøkt behandlet med legemidler før de fikk elektrokonvulsiv terapi, og 52 (37\%) hadde tidligere fått ECT-behandling. Det betyr at det som i denne artikkelen benevnes "første ECTserie», ikke nødvendigvis er første ECT-behandling pasienten mottar, men den første pasienten fikk ved Dikemark sykehus. ECTprosedyren, materialet, virkning og bivirkninger er beskrevet tidligere $(1,4)$.

Fra før 1960 fulgte legene utskrevne pasienter i ettervernet, og regelen var at de som fikk tilbakefall, ble reinnlagt i samme avdeling ved sykehuset.

Observasjonstid er definert som tiden etter avsluttet første ECT-serie ved Dike- mark sykehus til og med 31.12. 1995. Ved gjennomsyn av materialet hadde fem personer som fikk elektrokonvulsiv terapi i perioden 1960-95, fått sin første ECT-serie ved sykehuset før 1960. Disse fem seriene er også tatt med i materialet.

Tilbakefall ble definert som journalført klar tilbakekomst av depressive symptomer, dvs. reinnleggelse eller åpenbart fall i sosial fungering, behov for å forandre antidepressiv medikasjon eller mottak av ny ECT-serie, hos pasienter som hadde oppnådd bedring eller remisjon innen fire uker etter en serie med ECT-behandling.

Bedring ble klassifisert slik:

- Mye bedret (remisjon): Gjenvinning av premorbid funksjonsnivå med full remisjon av symptomer, noe som førte til at pasienten ble utskrevet fra sykehuset innen fire uker

- Bedret: Bedring av symptomer og funksjonsnivå, men med restsymptomer som førte til at pasienten ikke kunne utskrives fra sykehuset i løpet av de første fire ukene

Tilbakefall presenteres for totalmaterialet, for første og senere serier og etter variabler med antatt klinisk relevans (første serie): kjønn, alder, diagnose, indikasjon (vrangforestillinger/annet), indeksdepresjonens og sykehusoppholdets varighet, antall behandlinger i forste ECT-serie, bedringsgrad, hvor raskt bedringen viste seg, legemiddelbruk før elektrokonvulsiv terapi og legemiddelprofylakse etterpå.

Praksis når det gjaldt profylaktisk medikamentell behandling i perioden var å starte opp med et antidepressivum eller litium umiddelbart etter ECT-serien. Dersom pasienten sto på et antidepressivum eller litium fra før, var hovedregelen at det ble midlertidig seponert, mens man ofte fortsatte med

\section{Hovedbudskap}

- Det var høy tilbakefallsrate etter elektrokonvulsiv behandling, særlig de to første månedene

- Det var ingen tilbakefall etter ECTbehandling ved første depresjonsepisode

- Vanlig oppfølgende behandling gir ikke tilfredsstillende profylakse

- Det er behov for prospektive studier av andre forebyggende tiltak 


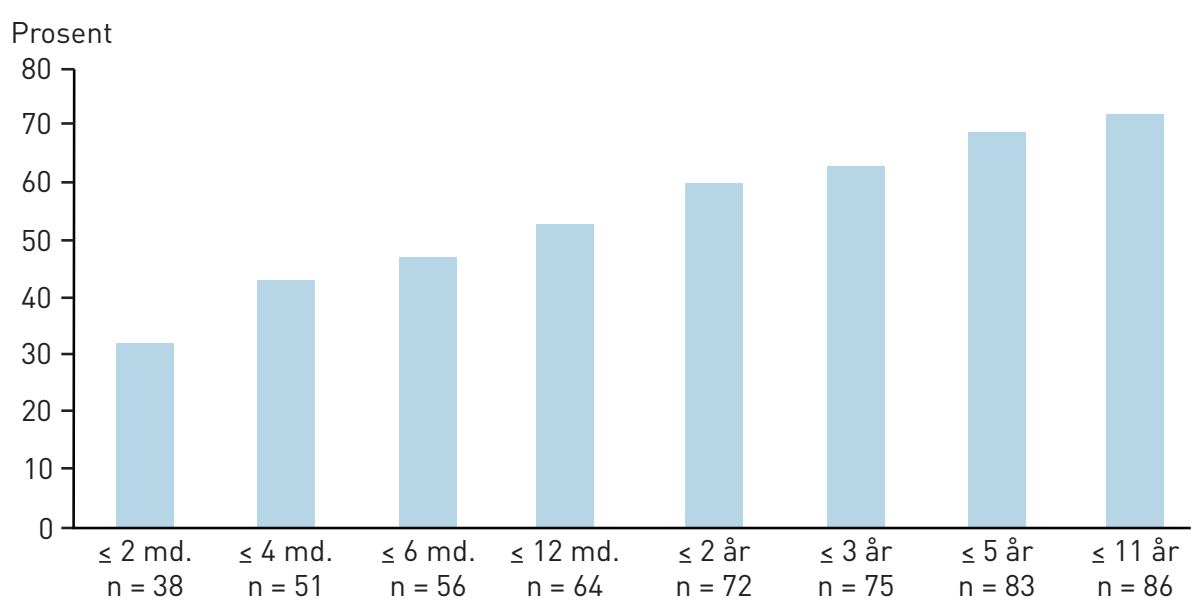

Figur 1 Prosentandel av bedrede og mye bedrede pasienter som fikk tilbakefall etter første ECT-serie ved Dikemark sykehus i perioden 1960-95, kumulert (n 120 av 141). Fem personer som fikk elektrokonvulsiv terapi i perioden 1960-95, hadde fătt sin første ECT-serie ved Dikemark sykehus før 1960. Disse fem seriene er tatt med i materialet

\section{Resultater}

legemidler for somatiske sykdommer og antipsykotika under serien.

\section{Etikk}

Studien er godkjent av personvernombudet ved Oslo universitetssykehus.

Tilbakefall etter førstegangsseriene $(n=141)$ Median observasjonstid var ni år (spredning: 3 md. -44 år). 86 av 120 (72\%) fikk tilbakefall, $38(32 \%)$ de første to månedene og 56 $(47 \%)$ innen det første halve året. Åtte personer $(7 \%)$ fikk tilbakefall det neste halvåret (fig 1). Gjennomsnittlig tid til tilbakefall var 13 måneder, median tid tre måneder.

\section{Undergrupper}

Ingen av de sju pasientene som ble bedre av sin førstegangs depressive episode fikk tilbakefall i løpet av en gjennomsnittlig observasjonstid på fire år (median 5 år), mot 56 av $71(79 \%)$ med tilbakevendende depresjon (e-tab 1).

I aldersgruppen 40-49 år var median tid til tilbakefall 30 måneder. Hos dem over 50 år var medianen 2-4 måneder (e-tab 1).

24 av 61 (39\%) som oppnådde remisjon og 32 av 59 (54\%) som responderte uten å oppnå remisjon fikk tilbakefall innen seks måneder.

Pasienter med sykehusopphold på seks

måneder eller mindre før ECT-behandlingen hadde en median tilbakefallstid på åtte måneder, mot to måneder ved sykehusopphold utover et halvt år. Av pasienter med opphold på over et halvt år fikk 24 av 53 (45\%) tilbakefall innen to måneder, mens 14 av 67 (21\%) med kortere opphold fikk så raskt tilbakefall.

De med fem eller færre ECT-behandlinger hadde en mediantid til tilbakefall på to måneder, mens det hos dem med 6-9 behandlinger gikk median fire måneder til tilbakefall. Hos dem som viste tegn til bedring innen tre dager, var median tid til tilbakefall sju måneder (e-tab 1).

Verken når det gjaldt kjønn, legemiddelbruk før elektrokonvulsiv terapi, indikasjon eller indeksdepresjonens varighet var det noen åpenbar sammenheng med andelen tilbakefall.

\section{Profylaktisk bruk av legemidler etter førstegangsseriene}

Etter første ECT-serie var det journalført at $78(65 \%)$ av de 120 som ble bedre, fikk et antidepressivum profylaktisk, derav 27 (23\%) i kombinasjon med et nevroleptikum og sju (6\%) i kombinasjon med litium. 13 ( $11 \%$ ) fikk både et nevroleptikum og litium. Tre (3\%) fikk kun litium, 15 (13\%) fikk et nevroleptikum alene og tre en kombinasjon. $21(18 \%)$ fikk ingen legemiddelprofylakse.

Tabell 2 Tilbakefall hos pasienter som ble bedre eller mye bedre i den første og de oppfølgende ECT-serier gitt ved Dikemark sykehus i perioden 1960-95 $(n=241)^{1}$

\begin{tabular}{lcccc}
$\begin{array}{l}\text { ECT- } \\
\text { serienummer }\end{array}$ & $\begin{array}{c}\text { Serier } \\
\text { Antall }\end{array}$ & $\begin{array}{c}\text { Serier med bedring } \\
\text { Antall (\%) }\end{array}$ & $\begin{array}{c}\text { Tilbakefall før } 6 \text { md. } \\
\text { Antall }(\%)\end{array}$ & $\begin{array}{c}\text { Tilbakefall totalt } \\
\text { Antall }(\%)\end{array}$ \\
\hline Serie 1 & 141 & $120(85)$ & $56(47)$ & $86(72)$ \\
\hline Serie 2-10 & $100^{2}$ & $87(87)$ & $58(67)$ & $75(86)$ \\
Alle seriene & $241^{2}$ & $207(86)$ & $114(55)$ & $161(78)$ \\
$\begin{array}{l}\text { 1Fem personer som fikk ECT-behandling i perioden 1960-95, hadde fått sin første ECT-serie ved } \\
\text { Dikemark sykehus før 1960. Disse fem seriene er tatt med i materialet }\end{array}$ \\
2 Behandlingsrespons kunne ikke vurderes hos én pasient
\end{tabular}

$81 \%$ av dem som fikk et antidepressivum alene og $76 \%$ av dem som ikke fikk noen profylakse, fikk tilbakefall. Tre av sju (43\%) fikk tilbakefall ved bruk av et antidepressivum og litium i kombinasjon. Uten profylakse var median tid til tilbakefall to måneder, mens den var tre måneder ved bruk av et antidepressivum og sju måneder ved bruk av et antidepressivum i kombinasjon med litium og/eller et nevroleptikum (e-tab 1).

Resultater av alle ECT-seriene ( $n=241)$

46 pasienter fikk en ECT-serie nummer to, og 24 av disse fikk serie nummer tre. En fikk hele ti serier. Av de 87 av til sammen 100 oppfølgende seriene hvor det ble registrert bedring, ble $58(67 \%)$ tilbakefall registrert innen seks måneder. Av totalt 207 serier med bedring ble det registrert 114 tilbakefall $(55 \%)$ innen seks måneder (tab 2).

\section{Diskusjon}

Etter initial bedring med elektrokonvulsiv terapi viser studien at det er stor grad av tilbakefall, flest det første halvåret. Dette er i tråd med resultatene fra andre studier (3). For tre pasienter skjedde det først etter 5-11 år, noe som påvirket gjennomsnittlig tid til tilbakefall.

Funnene støtter antakelsen at underdiagnosen av stemningslidelse er positivt assosiert med tilbakefallsrisikoen. I den lille gruppen med førstegangsdepresjon ble sju av ti bedre etter elektrokonvulsiv terapi og ingen fikk tilbakefall, mens tilbakefall var hyppig ved tilbakevendende depresjon og bipolar depresjon. Det kan se ut til at alderen er av betydning når det gjelder tid til tilbakefall (e-tab 1). Av seks 40-åringer fikk kun én tilbakefall i løpet av første halvår, selv om ingen hadde førstegangsdepresjon (data ikke vist).

Pasientgruppen hadde stor grad av legemiddelresistens, noe som kan ha bidratt til tilbakefall. Nesten halvparten hadde brukt to eller flere klasser antidepressiver før ECTserien, men det ser ikke ut til å ha påvirket tilbakefallsraten eller median tid til tilbakefall. Sackeim og medarbeidere fant høyere tilbakefallsrate hos dem som hadde fătt adekvat pre-ECT-farmakoterapi enn hos dem som ikke hadde fătt det $-64 \% \operatorname{mot} 32 \%$ (5).

Den høye forekomsten av tilbakefall kan ha sammenheng med at $18 \%$ av pasientene med bedring ikke mottok legemiddelprofylakse etter første ECT-serie, og at de fleste som fikk sekundærprofylakse, fikk antidepressiver som allerede hadde vist seg nytteløse mot depresjonen før ECT-behandlingen (data ikke vist). Hos dem som fikk en kombinasjon av et antidepressivum og litium og/eller et nevroleptikum, var det lavere tilbakefallsrate og lengre median tid til tilbakefall enn hos dem som fikk et antidepressivum alene.

I de 100 oppfølgende ECT-seriene som 46 pasienter fikk, var tilbakefallsprosenten noe høyere. Forklaringen kan være at 93 av disse seriene handlet om tilbakevendende eller bipolar depresjon (data ikke vist). 
Hva kan gjøres for å opprettholde remisjonen over tid? I en fersk oversikt finner man at psykoterapi alene eller i kombinasjon med antidepressiver etter elektrokonvulsiv terapi kan ha en positiv tilleggseffekt, uten at dette er noen robust strategi for å hindre tilbakefall (6).

Mange klinikker gir nå vedlikeholds-ECT for å forlenge remisjonsperioden og minske behovet for rehospitalisering når legemiddelbehandling ikke har kunnet forebygge tilbakefall (7). I en kontrollert retrospektiv studie fant man etter to år at $93 \%$ var uten alvorlig tilbakefall med vedlikeholds-ECT tillegg til kombinasjoner av legemidler, mot $52 \%$ uten vedlikeholds-ECT. Etter fem år var tallene $73 \%$ og $18 \%$ (8).

Lisanby og medarbeidere foreslår at man skal starte profylaktisk antidepressiv legemiddelbehandling allerede under ECT-serien og gi fire ECT-behandlinger den første måneden etter serien, siden risikoen for tilbakefall er størst da (9). Deretter undersøkes pasienten ukentlig for å bestemme behandlingsfrekvensen det neste halvåret. Denne tilnærmingen burde testes i en randomisert, kontrollert studie.

\section{Styrke og svakhet}

Styrker og svakheter er gjort rede for tidligere (1) og oppsummeres kort her. Materialet består av en selektert pasientgruppe og er basert på retrospektivt innhentede journalopplysninger. Selv om pasientene i regelen ble fulgt opp i ettervernet og reinnlagt i samme avdeling ved tilbakefall, er det ikke sikkert at alle tilbakefall er fanget opp. Jour- nalopplysningene var ikke gode nok til at man kunne vurdere om antidepressivene ble gitt i optimal dose over en adekvat tidsperiode og fastsette graden av etterlevelse av slik behandling. Eventuelt manglende etterlevelse kan være noe av forklaringen på den høye tilbakefallsfrekvensen.

Det er ikke utført multivariable analyser eller testet for mulig konfundering. Undergruppene i materialet var små, noe som gjør sammenlikningene usikre. Styrken er studiens naturalistiske form og at den favner over en lang tidsperiode.

\section{Konklusjon}

Tilbakefall av alvorlig depresjon etter vellykket elektrokonvulsiv terapi er vanlig, og dagens praksis for å forebygge tilbakefall er ikke god nok. Dette inviterer til prospektive studier av sekundærprevensjon hos depressive pasienter som får ECT-behandling.

Jeg takker Stein Opjordsmoen Ilner ved Oslo universitetssykehus, som har bidratt med gode råd.

e-tab 1 finnes kun i Tidsskriftets nettutgave.

\section{Kjell Martin Moksnes (f. 1942)}

er pensjonert spesialist i psykiatri med fordypningsområde alderspsykiatri. Han er deltidsansatt som overlege og prosjektmedarbeider ved Alderspsykiatrisk avdeling, Oslo universitetssykehus.

Ingen oppgitte interessekonflikter.
Litteratur

1. Moksnes KM, Opjordsmoen S. Elektrokonvulsiv terapi - virkning og bivirkninger. Tidsskr Nor Legeforen 2010; 130: 2460-4.

2. Reynolds CF 3rd, Frank E, Perel JM et al. Nortriptyline and interpersonal psychotherapy as maintenance therapies for recurrent major depression: a randomized controlled trial in patients older than 59 years. JAMA 1999: 281: 39-45.

3. Sackeim HA, Haskett RF, Mulsant BH et al. Continuation pharmacotherapy in the prevention of relapse following electroconvulsive therapy: a randomized controlled trial. JAMA 2001; 285 : 1299-307.

4. Moksnes KM, Vatnaland T, Eri B et al. Elektrokonvulsiv terapi i Ullevål sektor i Oslo 1988-2002. Tidsskr Nor Lægeforen 2006; 126: 1750-3.

5. Sackeim HA, Prudic J, Devanand DP et al. The impact of medication resistance and continuation pharmacotherapy on relapse following response to electroconvulsive therapy in major depression. J Clin Psychopharmacol 1990; 10: 96-104.

6. McClintock SM, Brandon AR, Husain MM et al. A systematic review of the combined use of electroconvulsive therapy and psychotherapy for depression. J ECT 2011; 27: 236-43.

7. Odeberg H, Rodriguez-Silva B, Salander P et al. Individualized continuation electroconvulsive therapy and medication as a bridge to relapse prevention after an index course of electroconvulsive therapy in severe mood disorders: a naturalistic 3-year cohort study. J ECT 2008; 24: 183-90.

8. Gagné GG Jr. Furman MJ, Carpenter LL et al. Efficacy of continuation ECT and antidepressant drugs compared to long-term antidepressants alone in depressed patients. Am J Psychiatry 2000; 157. $1960-5$.

9. Lisanby SH, Sampson S, Husain MM et al. Toward individualized post-electroconvulsive therapy care piloting the Symptom-Titrated, Algorithm-Based Longitudinal ECT (STABLE) intervention. J ECT 2008; 24: 179-82.

Mottatt 29.11. 2010, første revisjon innsendt 5.3. 2011, godkjent 15.9. 2011. Medisinsk redaktør Siri Lunde. 